\title{
The response of porcine monocyte derived macrophages and dendritic cells to Salmonella Typhimurium and lipopolysaccharide
}

Kamila Kyrova, Hana Stepanova, Ivan Rychlik, Ondrej Polansky, Lenka Leva, Zuzana Sekelova, Martin Faldyna and Jiri Volf*

\begin{abstract}
Background: Following infection and initial multiplication in the gut lumen, Salmonella Typhimurium crosses the intestinal epithelial barrier and comes into contact with cells of the host immune system. Mononuclear phagocytes which comprise macrophages and dendritic cells (DC) are of key importance for the outcome of Salmonella infection. Although macrophages and DC may differentiate from a common precursor, their capacities to process and present antigen differ significantly. In this study, we therefore compared the response of porcine macrophages and DC differentiated from peripheral blood monocytes to S. Typhimurium and one of the most potent bacterial pathogen associated molecular patterns, bacterial lipopolysaccharide. To avoid any bias, the expression was determined by protein LC-MS/MS and verified at the level of transcription by quantitative RT-PCR.

Results: Within 4 days of culture, peripheral blood monocytes differentiated into two populations with distinct morphology and expression of MHC II. Mass spectrometry identified 446 proteins in macrophages and 672 in DC. Out of these, 433 proteins were inducible in macrophages either after infection with $S$. Typhimurium or LPS exposure and 144 proteins were inducible in DC. The expression of the 46 most inducible proteins was verified at the level of transcription and the differential expression was confirmed in 22 of them. Out of these, 16 genes were induced in both cell types, 3 genes (VCAM1, HMOX1 and Serglycin) were significantly induced in macrophages only and OLDLR1 and CDC42 were induced exclusively in DC. Thirteen out of 22 up-regulated genes contained the NF-kappaB binding site in their promoters and could be considered as either part of the NF-kappaB feedback loop (IkappaBalpha and ISG15) or as NF-kappaB targets (IL1 beta, IL1alpha, AMCF2, IL8, SOD2, CD14, CD48, OPN, OLDLR1, HMOX1 and VCAM1).
\end{abstract}

Conclusions: The difference in the response of monocyte derived macrophages and DC was quantitative rather than qualitative. Despite the similarity of the responses, compared to DC, the macrophages responded in a more pro-inflammatory fashion.

Keywords: Macrophage, Dendritic cell, Porcine, LPS, Salmonella, Response

\footnotetext{
* Correspondence: volf@vri.cz

Veterinary Research Institute, Hudcova 70, Brno 621 00, Czech Republic
} 


\section{Background}

Pigs are one of the most important sources of animal proteins for the human population. However, due to intensive rearing, pigs are also highly susceptible to various pathogens including those with zoonotic potential. Salmonella enterica serovar Typhimurium is an example of a zoonotic agent for which pigs represent a reservoir for the human population. In fact, pigs represent the second most common source of Salmonella for humans after poultry and are the most important source if only serovar $S$. Typhimurium is considered.

Salmonella in pigs is transmitted by the oral-fecal route. Infections of pigs with $S$. Typhimurium are often asymptomatic [1] although mild diarrhea may be recorded at the early stage of infection [2,3]. After initial multiplication in the gut lumen, $S$. Typhimurium invades the intestinal epithelial cells and comes into contact with the host's immune system [4]. The innate immune responses of different parts of porcine intestinal tract have been repeatedly described [5-7]. Of the different leukocyte subpopulations, mononuclear phagocyte cells are of key importance for the outcome of Salmonella infection which comprise of macrophages $(\mathrm{M} \Phi)$ and dendritic cells $(\mathrm{DC})$. When these cells come into contact with bacterial pathogens, they recognize the pathogens through the presence of pathogen associated molecular patterns (PAMP) present in prokaryotic pathogens but absent from eukaryotic host cells. This leads to the modification of gene expression in $M \Phi$ and DC, and secretion of signaling molecules to coordinate responses of other cells of the host immune system. In addition, both $\mathrm{M} \Phi$ and DC are able to take up, process and present antigens to lymphocytes, thereby inducing the development of an adaptive immune response $[8,9]$.

Although only particular subsets of $M \Phi$ and DC can be differentiated from a monocyte precursor, their capacity to take up, process and present antigen differ significantly. There are several papers to date describing the expression profiles of selected genes in porcine monocytes, dendritic cells or macrophages in response to external stimuli [10-15]. However, these studies compared the responses either monocytes and monocyte derived dendritic cells (MoDC) [13], two differently generated macrophages [15] or two different DC populations [11,12]. The response of $M \Phi$ and $D C$ derived from monocytes has never been compared. Moreover, all the studies either determined the expression of preselected genes such as TLRs, MHC-II molecules, chemokines and cytokines by quantitative RT-PCR or used the Affymetrix microarray, so the measurements were limited to the level of transcription. Since the general understanding of antigen presentation and associated processes, especially in a porcine model, is far from being completely understood, in this study, we therefore differentiated porcine monocyte-derived macrophages (MoMФ) and MoDC, and compared their response to $S$. Typhimurium and one of the most potent bacterial PAMP, bacterial LPS. To avoid any bias, expression was determined by protein LC-MS/MS and verified at the level of transcription by QRT-PCR. Using such an approach, we concluded that the difference in the response of MoM $\Phi$ and MoDC was quantitative rather than qualitative, i.e. MoDC responded less extensively than MoMФ to LPS or $S$. Typhimurium stimulation.

\section{Results}

\section{Cell differentiation}

Depending on culture conditions, peripheral blood monocytes differentiated into two populations with distinct morphology within 4 days of culture. Adhered monocytes differentiated into MoMФ of spherical shape with characteristic short hairy protrusions on their surface. On the other hand, monocytes treated with IL4 and GM-CSF differentiated into MoDC characteristic by elongated cells with numerous dendrites typical of dendritic cells (Figure 1).

Flow cytometric analysis further confirmed the difference between the two cell populations. The most remarkable difference was a more than 40 times higher expression of MHC-II molecules on the surface of MoDC compared to MoMФ. The expression of CD14 and CD11a, when compared to $\mathrm{MoM} \Phi$, was numerically but not significantly higher in MoDC (Figure 2). On the other hand, expression of CD172 $\alpha$, CD16, CD163, CD45, TLR-2 and TLR-4 did not differ between both cell types (data not shown). The expression of surface molecules on MoDC and MoM $\Phi$ was also determined after $S$. Typhimurium infection. In response to infection, the amount of CD14 increased in both cell types whereas the expression of the remaining cell surface molecules did not change (Figure 2).

\section{Protein mass spectrometry}

The previous experiment showed that CD14 increased both in MoMФ and MoDC after $S$. Typhimurium infection. In the next experiment, we therefore determined what other proteins might have increased in expression in both MoMФ and MoDC. In addition to $S$. Typhimurium infection, protein expression was also determined in the LPS exposed cell cultures.

Mass spectrometry detected at least once 2191 proteins in MoMФ and 2204 proteins in MoDC [see Additional file 1]. However, when we applied the filter criteria described below, the number of proteins decreased to 446 proteins which were repeatedly detected in MoMФ and 672 in MoDC (Figure 3A). Out of the filtered proteins, 400 were detected in both MoM $\Phi$ and MoDC, 46 proteins were identified only in MoMФ and 272 proteins were identified 

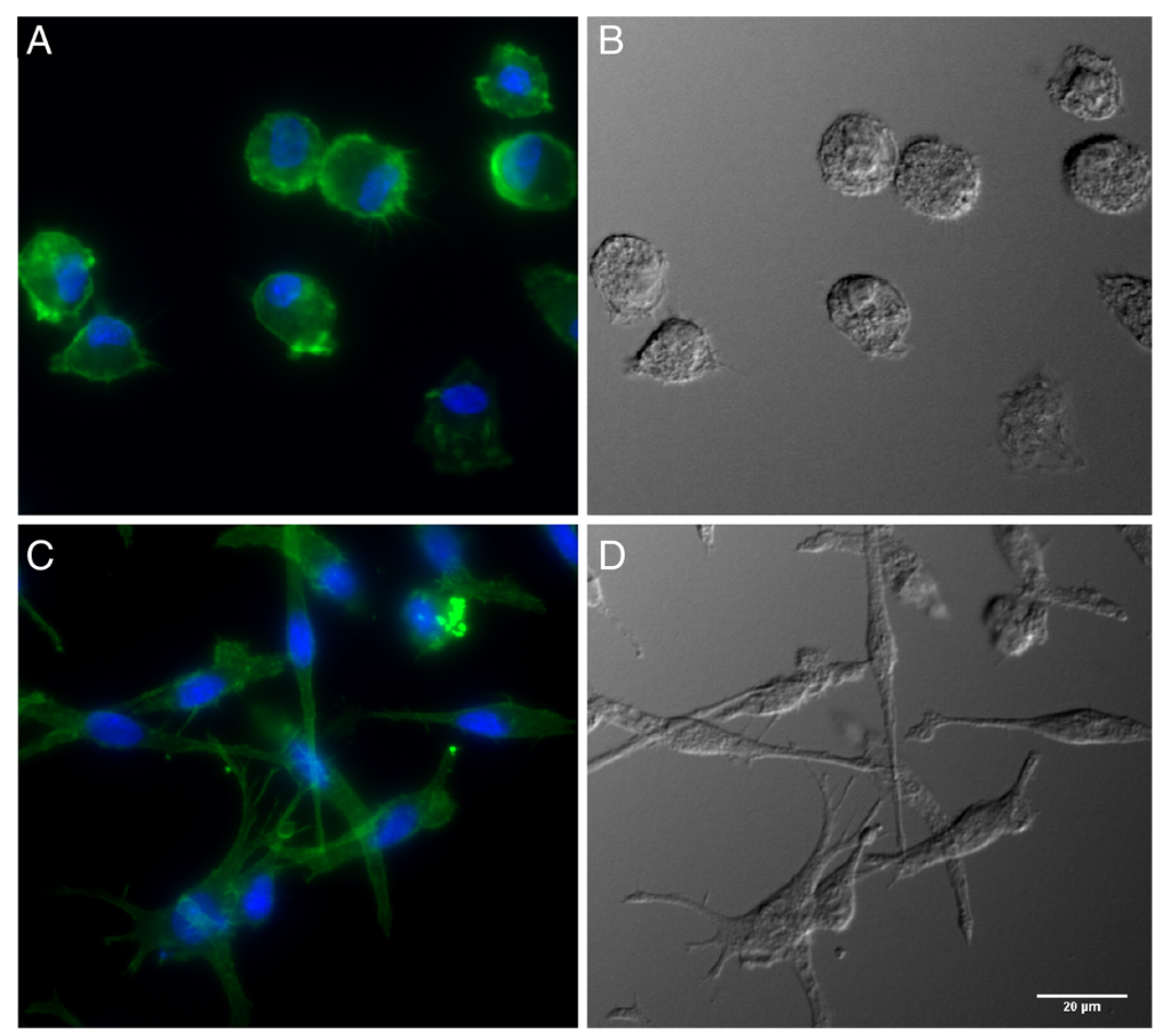

Figure 1 Cell morphology after differentiation of peripheral blood monocytes. Fluorescence microscopy and DIC was used to visualize differences in cell morphology. A and $\mathbf{B}, M \circ M \Phi, \mathbf{C}$ and $\mathbf{D}, \mathrm{MoDC}$. A and $\mathbf{C}$, fluorescence microscopy with nuclei stained in blue with DAPI and cytoskeleton stained in green with phalloidin. $\mathbf{B}$ and $\mathbf{D}, \mathrm{DIC}$.

only in MoDC. The comparison of the $M o M \Phi$ and MoDC response to LPS and $S$. Typhimurium showed that $M o M \Phi$ were more responsive as the number of proteins induced more than 2 fold was higher in MoMФ than in MoDC (Figure 3B). The MoMФ also showed a higher mean fold induction than the MoDC when comparing the proteins induced in both cell types [see Additional file 1].

\section{QRT-PCR}

Since mass spectrometry was performed in cells originating from only two donor pigs (Table 1), proteomic expression data were therefore confirmed at the transcriptional level by quantitative real-time PCR to which additional samples from 3 different pigs were included. Genes selected for QRT-PCR verification included those in which

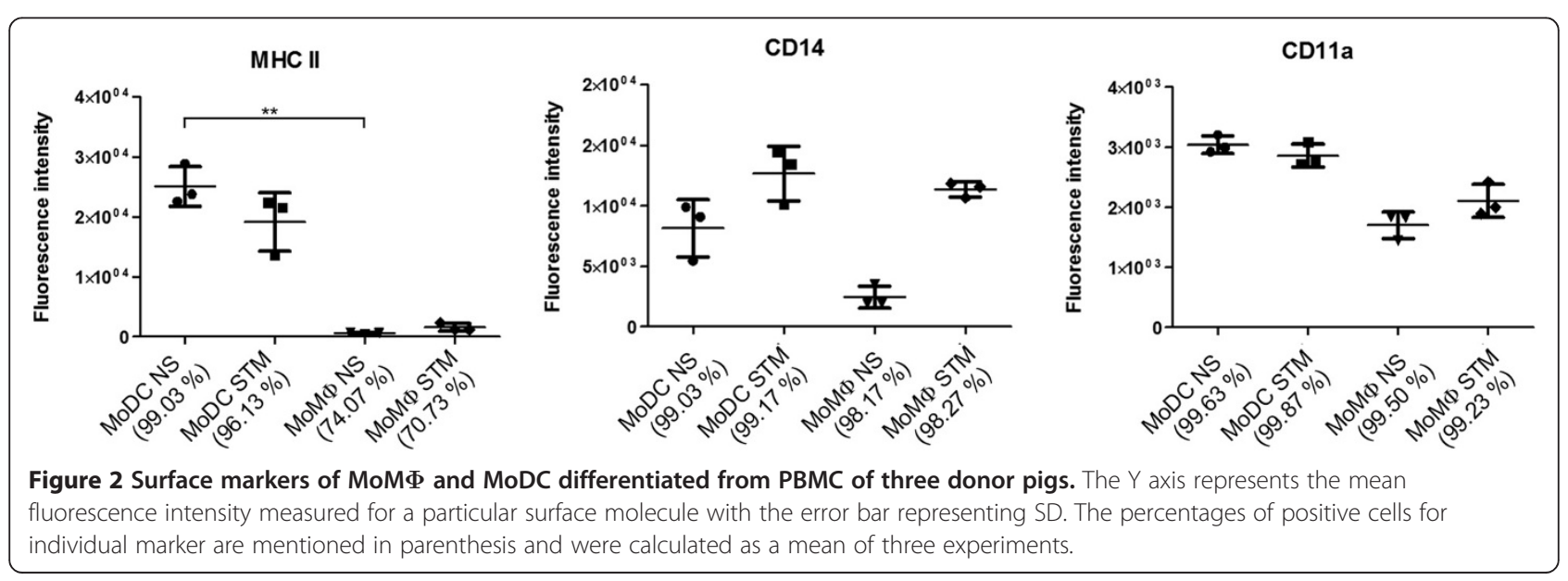



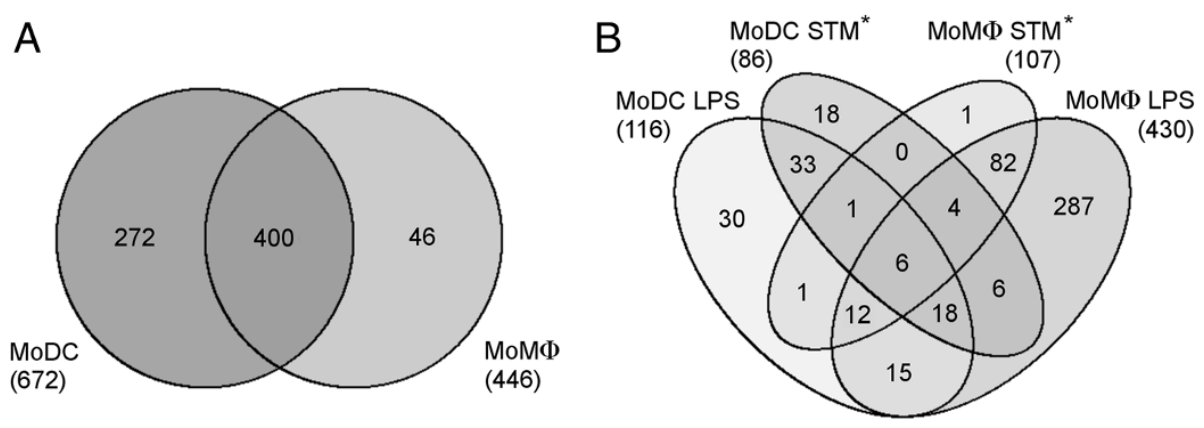

Figure 3 Numbers of proteins identified in MoM $\Phi$ and MoDC by LC-MS/MS analysis. Panel $\mathbf{A}$ Proteins expressed in both or either of the cell types. The number of proteins specific for each cell type might be actually lower as these were calculated after applying all filtering criteria described in Methods. Some of the MoDC proteins considered as specific in this figure can be low level expressed also in macrophages. The higher number of proteins expression of which was found to be induced twofold or more following individual stimulations (panel B) shows higher reactivity of MOM $\Phi$ in comparison with MoDC. *STM - S. Typhimurium.

the summed fold inductions determined by LC-MS/MS following LPS stimulation and $S$. Typhimurium infection exceeded a factor of 20 in the case of the less responsive $\mathrm{MoDC}$, or a factor of 30 in the case of the more responsive MoМФ. The selection resulted in 46 genes/proteins (see Additional file 2) and the differential expression was confirmed by QRT-PCR in 22 genes (Table 2).

Out of these, 16 genes were induced both in МoMФ and MoDC, 3 genes (VCAM1, HMOX1 and Serglycin) were significantly induced in MoMФ only and OLDLR1 and CDC42 were significantly induced exclusively in MoDC. Out of the 16 genes up-regulated in both cell types, 5 the most up-regulated ones encoded cytokines (IL1 $\beta$, AMCF2 (the porcine homolog of CXCL 5/6), CXCL2, IL8 and IL1 $\alpha$ ). In agreement with the proteomic data, the fold inductions determined by QRT-PCR were usually higher in $M o M \Phi$ than in MoDCs, despite the fact that the differences between MoMФ and MoDC responsiveness reached statistical significance only in 2 genes after exposure to LPS and 7 genes after infection with $S$. Typhimurium. This also means that the responsiveness of MoMФ and MoDCs to LPS was similar but DCs, unlike $M \Phi$, did not extensively respond to $S$. Typhimurium infection.

\section{Discussion}

In this study we were interested in the interactions of porcine MoMФ and MoDCs with LPS and S. Typhimurium. Both cell morphology and flow cytometry indicated that the culture conditions led to the differentiation of distinct cell types. Expression of surface molecules observed on MoDC was in agreement with the previous observations $[10,16]$. The up-regulation of CD14 in porcine alveolar macrophages following stimulation with LPS or Salmonella infection was also reported earlier $[10,17]$.

Similar responses to free LPS and S. Typhimurium of both cell types indicate that LPS is one of the dominant antigens of $S$. Typhimurium. The infection of MoMФ

Table 1 List of samples used in this study

\begin{tabular}{|c|c|c|c|c|c|}
\hline$\underline{P i g}$ & Cell culture & LC MS (NS/LPS/STM ${ }^{\dagger}$ ) & QRT PCR & FACS & Light microscopy \\
\hline 1 & A & & & Full FACS analysis* & Yes \\
\hline 2 & A & & & Full FACS analysis & Yes \\
\hline 3 & A & & & Full FACS analysis & Yes \\
\hline \multirow[t]{2}{*}{4} & $A^{\#}$ & Yes & Yes & CD14 check & Yes \\
\hline & $B^{\#}$ & Yes & Yes & CD14 check & Yes \\
\hline \multirow[t]{2}{*}{5} & $A^{\#}$ & Yes & Yes & CD14 check & Yes \\
\hline & $B^{\#}$ & Yes & Yes & CD14 check & Yes \\
\hline 6 & A & & Yes & CD14 check & Yes \\
\hline 7 & A & & Yes & CD14 check & Yes \\
\hline 8 & A & & Yes & CD14 check & Yes \\
\hline
\end{tabular}

${ }^{\dagger} \mathrm{NS}$ non stimulated cells, STM S. Typhimurium.

*Full analysis comprises the FACS measurement of the following surface markers: CD11a, CD14, CD16, CD45, CD163, CD172a, MHC-II, TLR2, TLR4. FACS analysis was performed only for untreated and $S$. Typhimurium infected cell cultures.

${ }^{\#}$ Two independent batches of MoM $\Phi$ and MoDC were obtained from these pigs. 
Table 2 Fold inductions of genes identified in this study in MoM $\Phi$ or MoDC in response to LPS or Salmonella Typhimurium (STM) exposure determined by QRT-PCR

\begin{tabular}{|c|c|c|c|c|c|c|c|c|c|}
\hline & MoDC & MoDC fold ir & Iction $\$$ & MoM $\Phi$ & MoM $\Phi$ fold & uction & Mo & to Mo & \\
\hline & Basal exp & STM & LPS & Basal exp & STM & LPS & NS & STM & LPS \\
\hline IL1B & $0.06 \pm 0.04$ & $106^{\#} \pm 101$ & $2358^{\#} \pm 1268$ & $0.11 \pm 0.06$ & $383^{\#} \pm 451$ & $1999^{\#} \pm 1743$ & $n$ & $*$ & $\mathrm{n}$ \\
\hline AMCF2 & $0.40 \pm 0.20$ & $35.3^{\#} \pm 33.0$ & $\mathbf{5 4 3}^{\#} \pm 528$ & $0.75 \pm 0.52$ & $115^{\#} \pm 107$ & $305^{\#} \pm 267$ & $\mathrm{n}$ & $\mathrm{n}$ & $\mathrm{n}$ \\
\hline CXCL2 & $0.71 \pm 0.28$ & $17.4^{\#} \pm 19.1$ & $200^{\#} \pm 161$ & $0.19 \pm 0.19$ & $155^{\#} \pm 102$ & $668^{\#} \pm 432$ & $n$ & $n$ & $n$ \\
\hline IL1A & $0.28 \pm 0.14$ & $\mathbf{2 2 . 9 ^ { \# }} \pm 25.3$ & 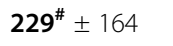 & $0.24 \pm 0.12$ & $86.5^{\#} \pm 48.8$ & $187^{\#} \pm 57$ & $n$ & $* *$ & $n$ \\
\hline IL8 & $15.3 \pm 13.7$ & $5.9 \pm 5.74$ & $34.2^{\#} \pm 21.6$ & $6.78 \pm 5.95$ & $\mathbf{2 2 . 9 ^ { \# } \pm 1 3 . 2}$ & $113^{\#} \pm 66$ & $n$ & $n$ & $n$ \\
\hline ISG15 & $0.88 \pm 0.52$ & $\mathbf{2 . 9 4 ^ { \# }} \pm 1.22$ & $2.00 \pm 0.94$ & $0.17 \pm 0.10$ & $22.1^{\#} \pm 2.0$ & $78.9^{\#} \pm 104.4$ & $* * *$ & $\mathrm{n}$ & $\mathrm{n}$ \\
\hline MARCKSL1 & $0.70 \pm 0.60$ & $1.82 \pm 0.63$ & $4.07^{\#} \pm 2.30$ & $0.25 \pm 0.08$ & $17.9^{\#} \pm 9.1$ & $\mathbf{4 2 . 9 ^ { \# } \pm 1 5 . 6}$ & $n$ & $*$ & $* *$ \\
\hline SOD2 & $4.28 \pm 4.58$ & $2.13 \pm 0.80$ & $12.8^{\#} \pm 12.9$ & $4.61 \pm 2.55$ & $11.3^{\#} \pm 4.6$ & $\mathbf{2 7 . 6} \mathbf{6}^{\#} \pm 11.6$ & $n$ & $* *$ & $n$ \\
\hline $\mathrm{IkBa}$ & $1.15 \pm 0.36$ & $\mathbf{2 . 7 4 ^ { \# } \pm 1 . 1 2}$ & $8.12^{\#} \pm 3.10$ & $1.13 \pm 0.57$ & $9.64^{\#} \pm 3.72$ & $15.1^{\#} \pm 4.8$ & $n$ & $* * *$ & $n$ \\
\hline CD14 & $0.52 \pm 0.19$ & $3.84^{\#} \pm 1.52$ & $14.4^{\#} \pm 9.6$ & $0.35 \pm 0.27$ & $14.0^{\#} \pm 9.7$ & $18.0^{\#} \pm 20.0$ & $\mathrm{n}$ & $n$ & $n$ \\
\hline PPA1 & $1.34 \pm 0.84$ & $1.85^{\#} \pm 0.7$ & $\mathbf{4 . 8 3 ^ { \# }} \pm 1.93$ & $1.39 \pm 0.17$ & $4.42^{\#} \pm 1.00$ & $7.02^{\#} \pm 1.73$ & $n$ & $* * *$ & $n$ \\
\hline CD48 & $7.35 \pm 4.25$ & $1.83 \pm 0.22$ & $3.2^{\#} \pm 1.8$ & $9.93 \pm 2.43$ & $3.34^{\#} \pm 0.71$ & $\mathbf{5 . 3 3 ^ { \# }} \pm 1.90$ & $n$ & * & * \\
\hline NF-KB1 & $1.57 \pm 0.41$ & $1.82 \pm 0.61$ & $3.49^{\#} \pm 1.4$ & $1.97 \pm 0.44$ & $2.25^{\#} \pm 0.7$ & $4.63^{\#} \pm 2.20$ & $n$ & $n$ & $n$ \\
\hline ANXA1 & $15.3 \pm 4.7$ & $1.78 \pm 0.9$ & $\mathbf{3 . 7 4 ^ { \# }} \pm 1.91$ & $22.9 \pm 13.4$ & $1.40 \pm 0.38$ & $2.45^{\#} \pm 1.01$ & $n$ & $n$ & $n$ \\
\hline OPN & $86.1 \pm 42.8$ & $2.33 \pm 1.5$ & $3.42^{\#} \pm 2.27$ & $138 \pm 72$ & $2.12 \pm 1.20$ & $3.81^{\#} \pm 2.00$ & $n$ & $n$ & $n$ \\
\hline PFDN2 & $0.09 \pm 0.03$ & $1.54 \pm 0.51$ & 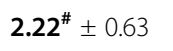 & $0.12 \pm 0.04$ & $2.12^{\#} \pm 0.60$ & $2.63^{\#} \pm 0.72$ & $n$ & $n$ & $n$ \\
\hline PSMB4 & $6.18 \pm 1.58$ & $1.42 \pm 0.30$ & $\mathbf{1 . 8 2 ^ { \# } \pm 0 . 3 1}$ & $7.34 \pm 1.39$ & $1.73 \pm 0.40$ & $\mathbf{2 . 1 1 ^ { \# } \pm 0 . 5 4}$ & $n$ & $\mathrm{n}$ & $\mathrm{n}$ \\
\hline MoDC only & & & & & & & & & \\
\hline OLDLR1 & $9.73 \pm 3.74$ & $1.95^{\#} \pm 0.5$ & $3.33^{\#} \pm 0.91$ & $26.2 \pm 3.0$ & $1.43 \pm 0.42$ & $1.62 \pm 0.41$ & $* * *$ & * & $n$ \\
\hline CDC42 & $3.52 \pm 0.70$ & $1.62^{\#} \pm 0.33$ & $1.63 \pm 0.33$ & $4.78 \pm 1.43$ & $1.60 \pm 0.13$ & $1.53 \pm 0.61$ & $n$ & $n$ & $n$ \\
\hline MoM $\Phi$ only & & & & & & & & & \\
\hline VCAM1 & $0.33 \pm 0.25$ & $2.32 \pm 1.90$ & $5.52 \pm 4.51$ & $0.18 \pm 0.19$ & $9.82^{\#} \pm 6.24$ & $18.9^{\#} \pm 13.6$ & $n$ & $n$ & $n$ \\
\hline HMOX1 & $0.32 \pm 0.20$ & $2.32 \pm 1.53$ & $1.42 \pm 0.51$ & $0.45 \pm 0.11$ & $\mathbf{2 . 3 4 ^ { \# }} \pm 1.11$ & $\mathbf{2 . 4 4 ^ { \# } \pm 0 . 1 4}$ & $n$ & $n$ & * \\
\hline Serglycin & $45.9 \pm 19.9$ & $1.52 \pm 0.71$ & $2.40 \pm 1.03$ & $35.7 \pm 28.9$ & $\mathbf{3 . 0 4}^{\#} \pm 1.32$ & $\mathbf{2 . 8 4 ^ { \# } \pm 1 . 3 3}$ & $\mathrm{n}$ & $\mathrm{n}$ & $\mathrm{n}$ \\
\hline
\end{tabular}

${ }^{\$}$ The fold inductions are presented as mean \pm SD calculated based on ratios of individual treated samples relative to the mean of appropriate non-stimulated control. "The numbers signed with " represent significantly different results compared to non-stimulated (NS) cells.

${ }^{*}$ Statistically significant differences between MoMФ and MoDC with the same treatment. ${ }^{*} p<0.05 ;{ }^{* *} p<0.01 ;{ }^{* * *} p<0.001 ; n=$ non-significant.

with $S$. Typhimurium did cause induction of only 3 additional proteins compared to LPS stimulated cells (Figure 3B). In case of MoDC there were 28 proteins solely induced by $S$. Typhimurium which represents less than one fifth of all proteins induced in MoDC. The higher stimulating potential of LPS compared to infection with $S$. Typhimurium was likely caused by the soluble character of LPS which was present in media and homogenously stimulated all the cells. On the other hand, only about $10 \%$ of cells were invaded by $S$. Typhimurium (data not shown), so the remaining uninfected cells could respond only to LPS released from bacterial cells into the medium during the experiments. The effect of indirect stimulation of infected cells toward their uninfected bystanders remains to be determined. Both LC-MS/MS and real-time PCR showed that the differences in the expression of genes inducible both in MoMФ and in MoDC were more pronounced in MoMФ. Together with the high expression of MHCII, this shows that the primary role of $\mathrm{DC}$ is antigen presentation whereas macrophages are involved in modulation of the environment by cytokine signaling.

Eleven genes/proteins, IL1 $\beta$, AMCF2, CXCL2, IL8, IL1 $\alpha$, ISG15, MARCKSL1, SOD2, IкB $\alpha$, CD14 and VCAM were induced by more than 10 fold. Out of these, IL1 $\beta$, CXCL2, AMCF2, IL8, IL1 $\alpha$ and the secreted form of ISG15 have a cytokine and/or chemokine function and their expression is related to the NF- $\mathrm{kB}$ dependent proinflammatory pathway. The central role of the NF- $\mathrm{kB}$ pathway is further supported by the fact that more than half of the identified genes (13 of 22) contain the NF- $k B$ binding site in the promoter. These genes could be considered as either involved in the NF- $\mathrm{kB}$ feedback loop ( $\mathrm{I} \kappa \mathrm{B} \alpha$ and ISG15) $[14,18]$ or act as NF- $\mathrm{B}$ targets: IL1 $\beta$, IL1 $\alpha$, AMCF2, IL8, SOD2, CD14, CD48, OPN, OLDLR1, HMOX1 and VCAM1 [17-28]. IL1 $\beta$, AMCF2, IL8, 
CXCL2, IL1 $\alpha$, MARCKSL1, SOD2, PPA1 and ISG15 were also found among the top $10 \%$ of the most inducible genes of bone marrow derived porcine macrophages treated with LPS [15].

The differences between MoMФ and MoDC responses were quite low. This could be caused by the fact that we selected the most inducible and highly abundant proteins, which had similar expression profiles following exposure to LPS or $S$. Typhimurium, and minority proteins responsible for the specificity of MoM $\Phi$ and MoDC remained unrecognized. The exceptions were represented by MARCKS-related gene/protein (MARCKSL1). This gene was expressed and induced in $\mathrm{MoM} \Phi$ after exposure to both LPS and $S$. Typhimurium at a significantly higher rate than in MoDC. Finally, its induction in LPS stimulated MoМФ was more than 40 fold indicating that this was a highly inducible gene.

MARCKSL1 (synonyms MLP, MacMARCKS, F52) is expressed mainly in the brain, reproductive tissues, and macrophages $[29,30]$ and belongs to a family of the unstructured proteins that mediate cross-talk in cell-to-cell signaling. MARCKSL1 is involved in the regulation of cell migration, adhesion and phagocytosis, as well as in neurosecretion and brain development [31-33]. Transcription of MARCKSL1 is also strongly increased upon stimulation with bacterial LPS [34-37]. Mancek-Keber et al. [38] showed that the MARCKSL1 protein binds LPS with an affinity sufficient enough to sequester a large fraction of the internalized LPS or intracellular Gram-negative bacteria within the endosome/phagosome.

\section{Conclusions}

In this study we have shown that $S$. Typhimurium and LPS in particular represent one of the most potent activators of signaling pathways of MoM $\Phi$ and MoDC leading to a similar response in both cell types. Despite the similarity of the responses, compared to MoDC, the MoMФ were more pro-inflammatory. This difference was less obvious in response to LPS and more obvious in response to $S$. Typhimurium. Our results showed that increased pro-inflammatory signaling by МoM $\Phi$ compared to MoDC might be, at least in some subsets of mononuclear phagocytes, associated with differential MARCKSL1 protein expression though the exact role of these proteins in differential responsiveness of MoM $\Phi$ and MoDC to $S$. Typhimurium infection remains to be determined.

\section{Methods}

\section{Differentiation of monocyte-derived macrophages and dendritic cells}

Blood was collected from healthy 8-10 month old conventional pigs kept at the Veterinary Research Institute for the educational purposes. The animal care protocol for this experiment followed the Czech guidelines for animal experimentation and was approved by the Branch Commission for Animal Welfare of the Ministry of Agriculture of the Czech Republic (permission No MZe 921). Peripheral Blood Mononuclear cells (PBMC) were isolated by gradient centrifugation using Histopaque1077 (Sigma-Aldrich). Monocytes were sorted from PBMC using indirect magnetic labelling based on the expression of CD14. In the first step, anti-CD14 monoclonal antibody (MIL-2, IgG2b, AbD Serotec) was used and consequently, the CD14-positive cells were captured by goat anti-mouse IgG MicroBeads (Miltenyi Biotec) and sorted using a QuadroMACS separator (Miltenyi Biotec) according to manufacturer's recommendations. The purity of the sorted cells was checked using a flow cytometer (LSR Fortessa, Becton Dickinson) with more than 90\% of the cells being CD14 positive. Approx. $5 \times 10^{5} \mathrm{CD}-14$ positive monocytes resuspended in $1 \mathrm{ml}$ of media were seeded per well on a 24-well microplate.

Half of the isolated monocytes were differentiated using protocol described previously [39] and the resulting cells were considered as MoDC throughout the study. RPMI-1640 medium (PAA) supplemented with antibiotics penicillin/streptomycin (Sigma-Aldrich), 10\% heatinactivated fetal calf serum (PAA), recombinant porcine IL4 $(50 \mathrm{ng} / \mathrm{ml}$, R\&D Systems) and GM-CSF $(20 \mathrm{ng} / \mathrm{ml}$, $R \& D$ Systems) was used. The second half of the cells were left to adhere to plastic microplates in DMEM (Gibco Invitrogen) supplemented with penicillin/streptomycin (Sigma-Aldrich) and 10\% heat-inactivated and filtered porcine serum (PAA) as described previously [40]. These cells were considered as MoMФ for the purposes of this study. Both MoM $\Phi$ and MoDC were differentiated at $37^{\circ} \mathrm{C}$ in a $5 \% \mathrm{CO}_{2}$ incubator for 4 days. $\mathrm{MoM} \Phi$ and MoDC were differentiated from peripheral blood monocytes from 8 different pigs, although not all of the cultures were used for all of the analyses (Table 1).

\section{Fluorescence microscopy and flow cytometry}

Differentiation of MoM $\Phi$ and MoDC was confirmed by flow cytometry and light microscopy. For light microscopy, the cells were grown on $13 \mathrm{~mm}$ glass slides as described above. After a 4-day culture, the cells were fixed with $4 \%$ paraformaldehyde and labelled with DAPI as a nuclear stain and Alexa Fluor (AF) 488 conjugated phalloidin (Invitrogen) to visualize the actin cytoskeleton. Microscopy was performed using epifluorescence inverted microscope Olympus IX81 equipped with PlanSAPO 40x (NA 0.95) objective using differential interference contrast (DIC), and fluorescence mode to detect DAPI and AF-488 fluorescence.

Cells for flow cytometry were harvested by $0.2 \%$ EDTA, washed in PBS and labelled with the following antibodies against surface proteins: anti-CD11a (BL1H8, 
IgG2b, AbD Serotec), anti-CD14 (MIL-2, IgG2b, AbD Serotec), anti-CD16 (G7, IgG1, AbD Serotec), anti-CD45 (K252.1E4, IgG1, gift from Dr. K. Haverson, University of Bristol, UK), anti-CD172 $\alpha$ (DH59B, IgG1, VMRD), anti-CD163 (2A100/11, IgG1, AbD Serotec), anti-MHCII (MSA3, IgG2a, VMRD), anti-TLR2 (1H11, IgG1, provided by Dr. J. Domiguez, Instituto Nacional de Investigación y Tecnología Agraria y Alimentaria, Madrid, Spain), and anti-TLR4 (HTA125, IgG2a, AbD Serotec). As the secondary antibody, AF 647-conjugated mouse isotype-specific goat antisera (Invitrogen) was used. Control samples were stained with secondary antibody only. The threshold for positive cells was set so that control cells stained by secondary antibody only remain $\geq 99 \%$ negative (not shown). Flow cytometry was performed using a LSR Fortessa flow cytometer operated by Diva software (Becton Dickinson).

\section{Bacteria and culture conditions}

Salmonella enterica serovar Typhimurium 16E5 of porcine origin belonging to phage-type DT104 [41] was used in this study. Bacteria were grown statically in LB broth at $37^{\circ} \mathrm{C}$ for 18 hours. This culture was diluted $800 \times$ in LB broth and incubated for an additional 6 hours at $37^{\circ} \mathrm{C}$ to obtain the bacteria in the late logarithmic growth-phase of highly invasive phenotype. Prior to infection of MoMФ and MoDC, the bacteria were collected by centrifugation and re-suspended in $\mathrm{PBS}$ to $\mathrm{OD}_{600}=0.3$.

\section{Experimental infection}

Prior to infection, the medium was replaced by serum free DMEM without antibiotics. MoM $\Phi$ and MoDC were infected with $S$. Typhimurium at a multiplicity of infection equal to 1 for $1 \mathrm{~h}$. Free bacteria were then washed away and gentamicin was added to fresh medium $(100 \mu \mathrm{g} / \mathrm{ml})$ to kill any remaining extracellular bacteria. One hour later, the medium was replaced with fresh medium containing $15 \mu \mathrm{g} / \mathrm{ml}$ gentamicin to prevent multiplication of extracellular bacteria that were eventually released during culture from dead cells. LPS from $S$. Typhimurium (Sigma-Aldrich) at a concentration of $1 \mu \mathrm{g} / \mathrm{ml}$ was used as another stimulus. Negative controls included an assay performed without any contact with $S$. Typhimurium or LPS. Eighteen hours after infection or LPS stimulation, the extracellular transport of proteins was blocked by the addition of $10 \mu \mathrm{g} / \mathrm{ml}$ of Brefeldin A (Sigma-Aldrich). Six hours later, the cells were washed with PBS and lysed by TRI reagent (Sigma-Aldrich) for RNA and protein purification.

\section{Mass spectrometry and proteome analysis}

Proteins from cell cultures were lysed with TRI Reagent and precipitated from the phenolic phase with acetone according to the manufacturer's recommendations. Dried protein pellets were dissolved in $300 \mu \mathrm{l}$ of $8 \mathrm{M}$ urea and processed by modified FASP method [42] using a Vivacon 500 device with MWCO of $10 \mathrm{kDa}$ (Sartorius Stedim Biotech). Dissolved proteins were washed twice with $8 \mathrm{M}$ urea and reduced by $10 \mathrm{~m} \mathrm{M} \mathrm{DTT}$. After reduction proteins were incubated with $50 \mathrm{mM}$ iodoacetamide and washed twice with $25 \mathrm{mM}$ triethylammonium bicarbonate buffer. Trypsin added to sample in 1:50 ratio (w/w) was used as digestive enzyme.

Tryptic peptides were labeled using the stable isotope dimethyl labeling method as described elsewhere [43]. Three combinations of formaldehyde and cyanoborohydride isotopomers were used for labelling; proteins from non-stimulated cells were labeled with a combination of $\mathrm{CH}_{2} \mathrm{O}$ and $\mathrm{NaBH}_{3} \mathrm{CN}$ (light tag), Salmonella-infected cells with $\mathrm{CD}_{2} \mathrm{O}$ and $\mathrm{NaBH}_{3} \mathrm{CN}$ (medium tag) and LPSstimulated cells with ${ }^{13} \mathrm{CD}_{2} \mathrm{O}$ and $\mathrm{NaBD}_{3} \mathrm{CN}$ (heavy tag). Prior to LC-MS/MS analysis, the labeled samples were mixed at a 1:1:1 ratio and analyzed in 3 independent LC-MS/MS runs using the Dionex UltiMate 3000 RSLC nano system connected to a Obitrap Velos Pro mass spectrometer (Thermo Scientific). Such setup enabled semi quantitative analysis of protein abundance. The injected sample was desalted and pre-concentrated during the first $3 \mathrm{~min}$ of LC-MS/MS run on the Acclaim PepMap C18 trapping column $(2 \mathrm{~cm} \times 75 \mu \mathrm{m}, 3 \mu \mathrm{m}$ particles) at a flow rate of $5 \mu \mathrm{l} / \mathrm{min}$ using the loading mobile phase consisting of $0.1 \%$ formic acid in $98 / 2 \mathrm{H}_{2} \mathrm{O} / \mathrm{ACN}$ (vol/vol). Chromatographic separation was performed on an EASY-Spray C18 separation column $(15 \mathrm{~cm} \times 75 \mu \mathrm{m}$, $3 \mu \mathrm{m}$ particles) at a flow rate of $400 \mathrm{nl} / \mathrm{min}$ using the acetonitrile gradient. High resolution (30,000 FWHM at $400 \mathrm{~m} / \mathrm{z}$ ) MS spectra were acquired for the 390-1700 m/z interval. Low resolution MS/MS spectra were acquired in Linear Ion Trap in a data-dependent manner - the top 10 precursors (in terms of abundance) were fragmented using CID fragmentation at a normalized collision energy of 35 .

Data were analyzed using the Proteome Discoverer (v.1.4). MS/MS spectra identification was performed by searching SEQUEST against the Sus scrofa database (Uniprot, on 4th of September, 2013) and precursor and fragment mass tolerance for searches were $10 \mathrm{ppm}$ and 0.6 Da respectively. Only peptides with a false discovery rate of $<1 \%$ were included in quantification. Only proteins which quantification was based on 12 or more particular peptide quantifications were considered as reliable. The peptide quantifications were based on ratios of peptide peak areas in stimulated and nonstimulated cells.

\section{RNA purification, reverse transcription and quantitative real-time PCR}

Total RNA was isolated from the water phase of TRIreagent using RNeasy kit (Qiagen) and immediately reverse transcribed using M-MLV reverse transcriptase (Invitrogen) 
and oligo-T primer. The resulting cDNA was diluted tenfold is sterile water and used as a template in QRTPCR immediately or was stored at $-20^{\circ} \mathrm{C}$ until use.

The mRNA sequences related to the LC-MS/MS identified proteins obtained from the GeneBank database were aligned to the genomic sequences using Spidey tool [44] and primers for QRT-PCR were designed over an introns using Primer3 software [45]. The complete list of primer used is available in Additional file 3. QRT-PCR was performed in $3 \mu \mathrm{l}$ volumes in 384-well-plate format using the QuantiTec SYBR Green PCR Kit (Qiagen) and Innovadyne Nanodrop pipetting station (IDEX Health \& Science LLC, Oak Harbor) for PCR mix dispensing. Amplification of PCR products and signal detection were performed using a LightCycler 480 (Roche) with an initial denaturation step at $95^{\circ} \mathrm{C}$ for $15 \mathrm{~min}$ followed by 40 cycles of PCR $\left(95^{\circ} \mathrm{C}\right.$ for $20 \mathrm{~s}, 60^{\circ} \mathrm{C}$ for $30 \mathrm{~s}$ and $72^{\circ} \mathrm{C}$ for $30 \mathrm{~s}$ ). Each sample was subjected to quantitative real-time PCR in triplicate and only replicates with correct curves and melting temperatures were included in the analysis. The mean values were calculated and used for subsequent analysis.

The expression levels of target genes were determined as follows. The threshold cycle values $\left(C_{t}\right)$ of genes of interest were normalized against the geometric mean of three the most stable genes identified according to Genorm algorithm [46]. These included hypoxanthine phosphoribosyl transferase I (HPRT), TATA box binding protein 1 (TBP1), and succinate dehydrogenase complex subunit A (SDHA). Tested, but excluded house-keeping genes, included HMBS, ACTB and GAPDH. Finally, the relative expression of each gene of interest was calculated as $2^{-\Delta C t}$.

\section{Statistical analysis}

Data are presented as the mean \pm SD or as a fold induction relative to the average expression in non-treated cells. However, for statistical analyses, Ct values obtained by QRT-PCR were used and the statistical significance was determined by one-way ANOVA with Tukey's post hoc test. (Prism, Graph Pad Software, La Jolla). Differences were considered significant if $p<0.05$.

\section{Additional files}

Additional file 1: The complete list of all proteins identified by LC-MS/MS any time in this study.

Additional file 2: The list of filtered proteins included in QRT-PCR verification.

Additional file 3: List of primers used in this study.

\section{Abbreviations}

ACN: Acetonitrile; ACTB: Actin Beta; AMCF2: Alveolar Macrophage Chemotactic Factor-2; CDC42: Cell Division Control Protein 42; CID: Collision-Induced Dissociation; CXCL2: Chemokine (C-X-C motif) Ligand 2; DTT: Dithiotreitol; FWHM: Full Width at Half Maximum; GAPDH: Glyceraldehyde 3-phosphate
Dehydrogenase; GM-CSF: Granulocyte-Macrophage Colony Stimulating Factor; HMBS: hydroxymethylbilane Synthase; HMOX1: Heme Oxygenase 1; HPRT: Hypoxanthine Phosphoribosyltransferase 1; IL1a: Interleukin-1 Alpha; IL1B: Interleukin-1 Beta; IL4: Interleukin-4; IL8: Interleukin-8; IKBa: Nuclear Factor of Kappa Light Polypeptide Gene Enhancer in B-cells Inhibitor Alpha; ISG15: Interferon Stimulated Gene-15; MARCKSL1: MARCKS-Related Protein; MWCO: Molecular Weight Cut-off; NF-KB: Nuclear Factor of Kappa Light Polypeptide Gene Enhancer in B-cells; OLDLR1: Oxidized Low Density Lipoprotein Receptor 1; OPN: Osteopontin; PAMP: Pathogen Associated Molecular Pattern; PBMC: Peripheral Blood Mononuclear Cells; PPA1: Pyrophosphatase (inorganic) 1; SDHA: Succinate Dehydrogenase Complex Subunit A; SOD2: Superoxid Dismutase; TBP1: TATA Box-Binding Protein; VCAM: Vascular Cell Adhesion Molecule 1.

\section{Competing interests}

The authors declare that they have no competing interests.

\section{Authors' contributions}

KK participated in the design of the study, carried out the cell cultures, light microscopy, QRT-PCR and helped to draft the manuscript. HS and LL carried out the cell isolation and the flow cytometry. OP and ZS carried out the proteomics. IR and MF helped to draft the manuscript. JV conceived of the study, and participated in its design and coordination and helped to draft the manuscript. All authors read and approved the final manuscript.

\section{Acknowledgements}

This study was supported by project MZE 0002716202, AdmireVet (CZ.105/ 2.1.00/01.0006) and MikroDok (CZ.1.07/2.3.00/30.0064). The funders had no role in study design, data collection and analysis, decision to publish, or preparation of the manuscript. Authors wish to thank Peter Eggenhuizen and Lee Clayton Elsheimer for their English language corrections. The authors got the permission to acknowledge them.

Received: 25 April 2014 Accepted: 24 September 2014

Published online: 01 October 2014

\section{References}

1. Kampelmacher EH, Edel W, Guinée PA, van Noorle Jansen LM: Experimental salmonella infections in pigs. Zentralblatt Für Veterinärmedizin Reihe $B J$ Vet Med Ser B 1969, 16:717-724.

2. Reed WM, Olander HJ, Thacker HL: Studies on the pathogenesis of salmonella typhimurium and salmonella choleraesuis var kunzendorf infection in weanling pigs. Am J Vet Res 1986, 47:75-83.

3. Schwartz KJ: Salmonellosis. In Diseases of Swine, 8th edition. Edited by Straw BE, D'Allaire S, Mengeling WL, Taylor DJ. Ames, lowa: lowa State University Press; 1999:535-551.

4. Berends BR, Urlings HA, Snijders JM, Van Knapen F: Identification and quantification of risk factors in animal management and transport regarding salmonella spp. In pigs. Int J Food Microbiol 1996, 30:37-53.

5. Meurens F, Berri M, Auray G, Melo S, Levast B, Virlogeux-Payant I, Chevaleyre C, Gerdts V, Salmon H: Early immune response following salmonella enterica subspecies enterica serovar typhimurium infection in porcine jejunal gut loops. Vet Res 2009, 40:5.

6. Collado-Romero M, Arce C, Ramírez-Boo M, Carvajal A, Garrido JJ: Quantitative analysis of the immune response upon salmonella typhimurium infection along the porcine intestinal gut. Vet Res 2010, 41:23

7. Martins RP, Collado-Romero M, Arce C, Lucena C, Carvajal A, Garrido JJ: Exploring the immune response of porcine mesenteric lymph nodes to salmonella enterica serovar typhimurium: an analysis of transcriptional changes, morphological alterations and pathogen burden. Comp Immunol Microbiol Infect Dis 2013, 36:149-160.

8. Rosenberger CM, Finlay BB: Phagocyte sabotage: disruption of macrophage signalling by bacterial pathogens. Nat Rev Mol Cell Biol 2003, 4:385-396.

9. Schnare M, Barton GM, Holt AC, Takeda K, Akira S, Medzhitov R: Toll-like receptors control activation of adaptive immune responses. Nat Immunol 2001, 2:947-950.

10. Carrasco CP, Rigden RC, Schaffner R, Gerber H, Neuhaus V, Inumaru S, Takamatsu H, Bertoni G, McCullough KC, Summerfield A: Porcine dendritic 
cells generated in vitro: morphological, phenotypic and functional properties. Immunology 2001, 104:175-184.

11. Auray G, Facci MR, van Kessel J, Buchanan R, Babiuk LA, Gerdts V: Differential activation and maturation of two porcine DC populations following TLR ligand stimulation. Mol Immunol 2010, 47:2103-2111.

12. Facci MR, Auray G, Buchanan R, van Kessel J, Thompson DR, Mackenzie-Dyck S, Babiuk LA, Gerdts V: A comparison between isolated blood dendritic cells and monocyte-derived dendritic cells in pigs. Immunology 2010, 129:396-405.

13. Raymond CR, Wilkie BN: Toll-like receptor, MHC II, B7 and cytokine expression by porcine monocytes and monocyte-derived dendritic cells in response to microbial pathogen-associated molecular patterns. Vet Immunol Immunopathol 2005, 107:235-247.

14. Sun SC, Ganchi PA, Ballard DW, Greene WC: NF-kappa B controls expression of inhibitor I kappa B alpha: evidence for an inducible autoregulatory pathway. Science 1993, 259:1912-1915.

15. Kapetanovic R, Fairbairn L, Beraldi D, Sester DP, Archibald AL, Tuggle CK, Hume DA: Pig bone marrow-derived macrophages resemble human macrophages in their response to bacterial lipopolysaccharide. J Immunol Baltim Md 1950 2012, 188:3382-3394.

16. Guzylack-Piriou L, Alves MP, McCullough KC, Summerfield A: Porcine Flt3 ligand and its receptor: generation of dendritic cells and identification of a new marker for porcine dendritic cells. Dev Comp Immunol 2010, 34:455-464.

17. Islam MA, Pröll M, Hölker M, Tholen E, Tesfaye D, Looft C, Schellander K, Cinar MU: Alveolar macrophage phagocytic activity is enhanced with LPS priming, and combined stimulation of LPS and lipoteichoic acid synergistically induce pro-inflammatory cytokines in pigs. Innate Immun 2013, 19:631-643.

18. Minakawa $\mathrm{M}$, Sone $\mathrm{T}$, Takeuchi $\mathrm{T}$, Yokosawa $\mathrm{H}$ : Regulation of the nuclear factor (NF)-kappaB pathway by ISGylation. Biol Pharm Bull 2008, 31:2223-2227.

19. Hiscott J, Marois J, Garoufalis J, D'Addario M, Roulston A, Kwan I, Pepin N, Lacoste J, Nguyen H, Bensi G: Characterization of a functional NF-kappa B site in the human interleukin 1 beta promoter: evidence for a positive autoregulatory loop. Mol Cell Biol 1993, 13:6231-6240.

20. Mori N, Prager D: Transactivation of the interleukin-1alpha promoter by human T-cell leukemia virus type I and type II Tax proteins. Blood 1996, 87:3410-3417.

21. Keates AC, Keates S, Kwon JH, Arseneau KO, Law DJ, Bai L, Merchant JL, Wang TC, Kelly CP: ZBP-89, Sp1, and nuclear factor-kappa B regulate epithelial neutrophil-activating peptide-78 gene expression in Caco-2 human colonic epithelial cells. J Biol Chem 2001, 276:43713-43722.

22. Kunsch C, Rosen CA: NF-kappa B subunit-specific regulation of the interleukin-8 promoter. Mol Cell Biol 1993, 13:6137-6146.

23. Xu Y, Kiningham KK, Devalaraja MN, Yeh CC, Majima H, Kasarskis EJ, St Clair DK: An intronic NF-kappaB element is essential for induction of the human manganese superoxide dismutase gene by tumor necrosis factor-alpha and interleukin-1beta. DNA Cell Biol 1999, 18:709-722.

24. Schumann RR: Mechanisms of transcriptional activation of lipopolysaccharide binding protein (LBP). Prog Clin Biol Res 1995, 392:297-304.

25. Klaman LD, Thorley-Lawson DA: Characterization of the CD48 gene demonstrates a positive element that is specific to epstein-barr virus-immortalized B-cell lines and contains an essential NF-kappa B site. J Virol 1995, 69:871-881.

26. Samant RS, Clark DW, Fillmore RA, Cicek M, Metge BJ, Chandramouli KH, Chambers AF, Casey G, Welch DR, Shevde LA: Breast cancer metastasis suppressor 1 (BRMS1) inhibits osteopontin transcription by abrogating NF-kappaB activation. Mol Cancer 2007, 6:6

27. Nagase M, Abe J, Takahashi K, Ando J, Hirose S, Fujita T: Genomic organization and regulation of expression of the lectin-like oxidized low-density lipoprotein receptor (LOX-1) gene. J Biol Chem 1998, 273:33702-33707.

28. Lavrovsky Y, Schwartzman ML, Levere RD, Kappas A, Abraham NG: Identification of binding sites for transcription factors NF-kappa B and AP-2 in the promoter region of the human heme oxygenase 1 gene. Proc Natl Acad Sci U S A 1994, 91:5987-5991.

29. Aderem $A$ : The role of myristoylated protein kinase $C$ substrates in intracellular signaling pathways in macrophages. Curr Top Microbiol Immunol 1992, 181:189-207.

30. Blackshear PJ: The MARCKS family of cellular protein kinase $\mathrm{C}$ substrates. J Biol Chem 1993, 268:1501-1504.

31. Yue L, Lu S, Garces J, Jin T, Li J: Protein kinase C-regulated dynamitinmacrophage-enriched myristoylated alanine-rice $\mathrm{C}$ kinase substrate interaction is involved in macrophage cell spreading. J Biol Chem 2000, 275:23948-23956.

32. Wu M, Chen DF, Sasaoka T, Tonegawa S: Neural tube defects and abnormal brain development in F52-deficient mice. Proc Natl Acad Sci U S A 1996, 93:2110-2115.

33. Chen J, Chang S, Duncan SA, Okano HJ, Fishell G, Aderem A: Disruption of the MacMARCKS gene prevents cranial neural tube closure and results in anencephaly. Proc Natl Acad Sci U S A 1996, 93:6275-6279.

34. Seykora JT, Ravetch JV, Aderem A: Cloning and molecular characterization of the murine macrophage "68-kDa" protein kinase $\mathrm{C}$ substrate and its regulation by bacterial lipopolysaccharide. Proc Natl Acad Sci U S A 1991, $88: 2505-2509$.

35. Sunohara JR, Ridgway ND, Cook HW, Byers DM: Regulation of MARCKS and MARCKS-related protein expression in BV-2 microglial cells in response to lipopolysaccharide. J Neurochem 2001, 78:664-672.

36. Rosé SD, Byers DM, Morash SC, Fedoroff S, Cook HW: Lipopolysaccharide stimulates differential expression of myristoylated protein kinase $C$ substrates in murine microglia. J Neurosci Res 1996, 44:235-242.

37. Chang S, Stacey KJ, Chen J, Costelloe EO, Aderem A, Hume DA: Mechanisms of regulation of the MacMARCKS gene in macrophages by bacterial lipopolysaccharide. J Leukoc Biol 1999, 66:528-534.

38. Mancek-Keber M, Bencina M, Japelj B, Panter G, Andrä J, Brandenburg K, Triantafilou M, Triantafilou K, Jerala R: MARCKS as a negative regulator of lipopolysaccharide signaling. J Immunol Baltim Md 1950 2012, 188:3893-3902.

39. Wang X, Eaton M, Mayer M, Li H, He D, Nelson E, Christopher-Hennings J: Porcine reproductive and respiratory syndrome virus productively infects monocyte-derived dendritic cells and compromises their antigen-presenting ability. Arch Virol 2007, 152:289-303.

40. Stepanova H, Pavlova B, Stromerova N, Ondrackova P, Stejskal K, Slana I, Zdrahal Z, Pavlik I, Faldyna M: Different immune response of pigs to Mycobacterium avium subsp. avium and Mycobacterium avium subsp. hominissuis infection. Vet Microbiol 2012, 159:343-350.

41. Pavlova B, Volf J, Ondrackova P, Matiasovic J, Stepanova H, Crhanova M, Karasova D, Faldyna M, Rychlik I: SPI-1-encoded type III secretion system of Salmonella enterica is required for the suppression of porcine alveolar macrophage cytokine expression. Vet Res 2011, 42:16.

42. Wiśniewski JR, Zougman A, Nagaraj N, Mann M: Universal sample preparation method for proteome analysis. Nat Methods 2009, 6:359-362.

43. Boersema PJ, Raijmakers R, Lemeer S, Mohammed S, Heck AJR: Multiplex peptide stable isotope dimethyl labeling for quantitative proteomics. Nat Protoc 2009, 4:484-494.

44. Wheelan SJ, Church DM, Ostell JM: Spidey: a tool for mRNA-to-genomic alignments. Genome Res 2001, 11:1952-1957.

45. Koressaar T, Remm M: Enhancements and modifications of primer design program Primer3. Bioinforma Oxf Engl 2007, 23:1289-1291.

46. Vandesompele J, De Preter K, Pattyn F, Poppe B, Van Roy N, De Paepe A, Speleman F: Accurate normalization of real-time quantitative RT-PCR data by geometric averaging of multiple internal control genes. Genome Biol 2002, 3(7):RESEARCH0034

doi:10.1186/s12917-014-0244-1

Cite this article as: Kyrova et al:: The response of porcine monocyte derived macrophages and dendritic cells to Salmonella Typhimurium and lipopolysaccharide. BMC Veterinary Research 2014 10:244.

\section{Submit your next manuscript to BioMed Central and take full advantage of:}

- Convenient online submission

- Thorough peer review

- No space constraints or color figure charges

- Immediate publication on acceptance

- Inclusion in PubMed, CAS, Scopus and Google Scholar

- Research which is freely available for redistribution 